\title{
Analysis of non-alcoholic fatty liver disease microRNA expression spectra in rat liver tissues
}

\author{
JIAO NIE ${ }^{1}$, CHANG-PING LI ${ }^{1}$, JUE-HONG LI ${ }^{2}$, XIA CHEN $^{1}$ and XIAOLING ZHONG ${ }^{1}$ \\ ${ }^{1}$ Department of Gastroenterology, Affiliated Hospital of Southwest Medical University, Luzhou, Sichuan 646000; \\ ${ }^{2}$ Graduate School, College of Medicine, Shanghai Jiao Tong University, Shanghai 200025, P.R. China
}

Received January 24, 2018; Accepted June 14, 2018

DOI: $10.3892 / \mathrm{mmr} .2018 .9268$

\begin{abstract}
The prevalence of non-alcoholic fatty liver disease (NAFLD) has been increasing in recent years. Previous studies have suggested that micro (mi)RNAs may be involved in the pathogenesis of NAFLD. To investigate the role of miRNAs in rat NAFLD, a total of 16 male Sprague Dawley rats were randomly divided into a control group and a model group. Rats in the control group were fed a normal diet for 12 weeks, whereas the rats in the model group were fed a high-fat and high-sugar diet for 12 weeks. Following this, the animals were sacrificed and liver tissues were rapidly removed to investigate the severity of NAFLD. Blood samples were collected to investigate liver function, in addition to total cholesterol, total triglyceride and fasting plasma glucose levels. Total RNA from three fresh liver samples per experimental group was extracted for subsequent miRNA gene chip analysis using GeneChip miRNA 4.0 to investigate differentially expressed miRNAs, and miRNA expression was further verified via reverse transcription-quantitative polymerase chain reaction (RT-qPCR). Compared with the control group, the results revealed that there were 10 differentially expressed miRNAs in the model group, five of which were overexpressed and five of which were underexpressed compared with the control group. The results of the RT-qPCR analysis revealed that miR-182, miR-29b-3p and miR-741-3p were significantly overexpressed in the model group compared with the control group, which was largely consistent with the results of the microarray analysis. The results suggested that the differentially expressed microRNAs demonstrated in the present study may be involved in the pathogenesis of NAFLD; however, the mechanism underlying the differential expression of miRNAs in NAFLD requires further investigation.
\end{abstract}

Correspondence to: Professor Chang-Ping Li, Department of Gastroenterology, Affiliated Hospital of Southwest Medical University, 25 Taiping Street, Luzhou, Sichuan 646000, P.R. China E-mail: 506854209@qq.com

Key words: non-alcoholic fatty liver disease, microRNA, analysis, rat liver tissue

\section{Introduction}

Non-alcoholic fatty liver disease (NAFLD) is rapidly becoming the most common form of liver disease worldwide (1). NAFLD is defined as evidence of hepatic steatosis, revealed either by biopsy or imaging techniques, in the absence of substantial alcohol intake, viral hepatitis, steatogenic medications or congenital metabolic disorders (2). NAFLD has become an important public health issue due to its high prevalence, which has been estimated to be between 20-30\% in the USA and Canada and 15-30\% in China (3). NAFLD is commonly associated with obesity, type 2 diabetes mellitus, dyslipidemia and hypertension; NAFLD has also been regarded as a hepatic manifestation of metabolic syndrome (4).

The pathogenesis of NAFLD remains unclear; however, the 'two-hit' hypothesis is the most widely accepted theory. The hypothesis states that fat deposition in the liver represents the 'first hit'; and increased levels of oxidative stress, insulin resistance and inflammatory cytokines induced by fat deposition in the liver represents the 'second hit', and which leads to the occurrence of NAFLD (5). However, Tilg and Moschen (6) developed the 'multi-parallel combat' theory, which suggested that the adipose degeneration of hepatocytes was the adaptive response but not the trigger factor of NAFLD. In addition, concurrent cytokine-mediated oxidative stress has been previously demonstrated to be the predominant inducer of necrotizing granulomatous inflammation in the liver and induces the development of NAFLD (7). Until now, no therapeutic treatments have proven effective for the treatment of NAFLD, and the treatment of NAFLD predominantly lies in lifestyle management (4). Over the past decade, it has been demonstrated that micro (mi)RNAs may have a role in the pathogenesis of NAFLD (8). In the present study, the miRNA expression spectrum in rat liver tissues was investigated to determine the miRNAs associated with the pathogenesis of NAFLD. The results of the present study lay the foundation for further study regarding the pathogenesis of NAFLD.

\section{Materials and methods}

Materials. Male Sprague Dawley (SD) rats purchased from Chongqing Kechuang Animal Center (Chongqing, China; $\mathrm{n}=16$; weight, $200 \mathrm{~g}$; aged 4 weeks), cholesterol, sodium cholate (Shanghai Lan Ji Technology Development Co., Ltd., 
Shanghai, China), TRIzol reagent (Invitrogen; Thermo Fisher Scientific, Inc., Waltham, MA, USA), an Agilent RNA 6000 Nano kit (Agilent Technologies, Inc., Santa Clara, CA, USA), a FlashTag Biotin HSR RNA Labeling kit (Affymetrix; Thermo Fisher Scientific, Inc.), a GeneChip Hybridization Wash and Stain kit (Affymetrix; Thermo Fisher Scientific, Inc.), a First Strand cDNA Synthesis kit (Toyobo Life Science, Osaka, Japan), Taq DNA Polymerase (Thermo Fisher Scientific, Inc.) and a SYBR ${ }^{\circledR}$ Premix Ex Taq ${ }^{\mathrm{TM}}$ kit (Takara Bio, Inc., Otsu, Japan) were purchased. The composition of the high-sugar and high-fat diet was as follows: $82.5 \%$ common feed, $10 \%$ lard, $5 \%$ sucrose, $2 \%$ cholesterol and $0.5 \%$ sodium cholate.

Establishment of the NAFLD animal model. A total of 16 male SD rats were randomly divided into a control group and a model group ( 8 rats per group) following 1 week of adaptive feeding with common feed. Rats were housed at $20 \pm 5^{\circ} \mathrm{C}$, a light/dark cycle of $12 / 12 \mathrm{~h}$ and a humidity of $50 \%$, with free access to water and food. Following this, the control group was fed ordinary feed, and the model group was fed a high-sugar and high-fat diet. Following 12 weeks of treatment, animals were sacrificed and liver tissues were removed for subsequent analysis. Furthermore, blood samples were collected from the abdominal aortas for biochemical analysis. This study was approved by the Ethics Committee of Affiliated Hospital of the Southwest Medical University (Luzhou, China; no. 20150028).

Liver specimens and hematoxylin and eosin $(H \& E)$ staining. Fresh liver samples were fixed in $4 \%$ neutral formaldehyde for $24 \mathrm{~h}$ and then embedded in paraffin. Liver tissues were sliced into $5 \mu \mathrm{m}$ sections using a thin semiautomatic microtome. Following this, sections were attached to glass slides and then incubated at $80^{\circ} \mathrm{C}$ for $2 \mathrm{~h}$. Following this, sections were stained using $0.4 \%$ hematoxylin for $5 \mathrm{~min}$ and $0.5 \%$ eosin for $30 \mathrm{sec}$ at room temperature. Following this, the NAFLD activity scores (NAS) of liver tissues slices were determined, and liver fibrosis stages were blindly graded by two pathologists according to the global guidelines for Non-alcoholic Fatty Liver and NASH (9). The NAFLD activity score (NAS) was determined according to the weighted sum of hepatocyte steatosis (0-3 points according to its severity), lobular inflammation (0-3 points according to its severity) and hepatocyte ballooning (0-2 points according to its severity).

Detection of biochemical markers. Plasma $(2 \mathrm{ml})$ was used to determine the levels of aspartate aminotransferase (AST), alanine aminotransferase (ALT), total triglyceride (TG), total cholesterol (TC) and fasting plasma glucose (FPG) using Aspartate Aminotransterase Reagents, Alanine Aminotransterase Reagents, Triglycerides_2 Reagents, Cholesterol_2 Reagents and Glucose Hexokinase_3 Reagents kits, respectively (Siemens AG, Munich, Germany). Following this, the ADVIA 2400 chemistry system was used according to instruction of the test kit.

Extraction and quality assay of total RNA in the liver tissues. Fresh liver tissues of the control group and model group were quickly cut into small pieces and then immediately placed in $2 \mathrm{ml}$ cryopreservation tubes. Following this, tissues were placed in liquid nitrogen as soon as possible for frozen storage and then placed in a $-80^{\circ} \mathrm{C}$ freezer for $1 \mathrm{~h}$ for cold storage. Following this, tissues were treated with TRIzol reagent $(1 \mathrm{ml}$ TRIzol/50-100 mg liver tissue) and the tissues were fully homogenated and subsequently placed on ice. The liquid was subsequently transferred to a $1.5 \mathrm{ml}$ non-nuclease centrifuge tube and incubated at room temperature for $5 \mathrm{~min}$. Following this, chloroform ( $0.2 \mathrm{ml}$ chloroform/1 ml TRIzol) was added and following rapid oscillation, the sample was incubated at room temperature for $2 \mathrm{~min}$. The liquid was centrifuged at $4^{\circ} \mathrm{C}$ and $12,000 \mathrm{x} \mathrm{g}$ for $15 \mathrm{~min}$ and then separated into three layers, which included a colorless water phase, a protein phase and a pink organic phase from top to bottom, respectively. The supernatant was removed and transferred to a clean $1.5 \mathrm{ml}$ nuclease-free Eppendorf (EP) tube, isopropyl alcohol $(\sim 0.5 \mathrm{ml})$ was added and the tube was then incubated for $\sim 10 \mathrm{~min}$ at room temperature. The sample was subsequently centrifuged at $4^{\circ} \mathrm{C}$ and $12,000 \times \mathrm{g}$ for $15 \mathrm{~min}$ to precipitate the RNA. The supernatant liquid was removed, $1 \mathrm{ml}$ of $75 \%$ ethanol was added and the liquid was subsequently centrifuged for $10 \mathrm{~min}$ at $4^{\circ} \mathrm{C}$ at 7,500 $\mathrm{x}$ g. The precipitate was washed twice with diethylpyrocarbonate water for maximum removal of residual ethanol from the EP tube wall and incubated at room temperature for 5-10 $\mathrm{min}$. Once the precipitate became translucent, nuclease-free water was added to dissolve the precipitate. The RNA concentration and A260/A280 ratio were determined using a Thermo Fisher Scientific, Inc. NanoDrop2000 ultramicrospectrophotometer (Wilmington, DE, USA). The results revealed that the ratio was $1.7: 2.2$, which indicated a high purity of the extracted RNA, which was deemed suitable for subsequent analysis. Following this, a total of $1 \mu \mathrm{g}$ RNA was used for $1 \%$ agarose gel electrophoresis. The ratio of $28 \mathrm{~S} / 18 \mathrm{~S}$ was then determined using an Agilent 2100 Bioanalyzer (Agilent Technologies, Inc.) to determine the quality of RNA. If the RNA integrity number $(\mathrm{RIN})>=7.0$ and $28 \mathrm{~S} / 18 \mathrm{~S}>0.7$, samples were deemed adequate for subsequent chip screening. TargetScan (http://www.targetscan.org/mmu_71/), miRDB (http://www.mirdb.org/) and microRNA.org (http://www.mirbase.org/index.shtml) were used to predict differentially expressed miRNAs in liver tissues.

Detection of miRNA expression profiles. The qualifying extracted RNA samples were added to fresh hybridization reaction solutions post-labeling. A poly(A) tail was subsequently added (Poly A polymerase, 0.2-2.0 U/ $\mu 1$ ) and subsequently incubated for $15 \mathrm{~min}$ at $37^{\circ} \mathrm{C}$. Following this, biotin labeling was performed using a FlashTag Biotin HSR RNA Labeling kit (Affymetrix; Thermo Fisher Scientific, Inc.). Following incubation at $99^{\circ} \mathrm{C}$ for $5 \mathrm{~min}$ and $45^{\circ} \mathrm{C}$ for $5 \mathrm{~min}$, the reaction solutions were added to the GeneChip miRNA 4.0 (Affymetrix; Thermo Fisher Scientific, Inc.). Chips were hybridized for 16-18 h in a GeneChip Hybridization Oven 645 (Affymetrix; Thermo Fisher Scientific, Inc.) at $48^{\circ} \mathrm{C}$ and $60 \mathrm{rpm}$. Chips were scanned using a GeneChip Scanner 3000 (Affymetrix; Thermo Fisher Scientific, Inc.) washed with GeneChip Hybridization Wash and Stain Kit (Affymetrix; Thermo Fisher Scientific, Inc.) and then scanned using GeneChip Scanner 3000 (Affymetrix; Thermo Fisher Scientific, Inc.). Following this, the original data were subtracted the background data and normalized in order to determine the miRNAs exhibiting a $>2$ fold change in rats with NAFLD compared with healthy rats. 
Table I. Statistical analysis of liver index and other indexes.

\begin{tabular}{lcccr}
\hline Group & Weight pre-modeling, $g$ & Weight post-modeling, $g$ & Liver wet weight, g & Liver index, \% \\
\hline Control & $198.5500 \pm 22.0300$ & $433.7900 \pm 38.7800$ & $10.8900 \pm 1.3000$ & $0.0250 \pm 0.0015$ \\
Model & $223.7800 \pm 34.8800$ & $432.1600 \pm 72.0400$ & $13.3500 \pm 3.3900$ & $0.0310 \pm 0.0049^{\mathrm{a}}$
\end{tabular}

${ }^{\mathrm{a}} \mathrm{P}<0.05$ vs. control group.

Table II. Statistical analysis of biochemical indicators.

\begin{tabular}{|c|c|c|c|c|c|}
\hline Group & ALT, U/1 & AST, U/l & $\mathrm{TC}, \mathrm{mmol} / \mathrm{l}$ & $\mathrm{TG}, \mathrm{mmol} / \mathrm{l}$ & $\mathrm{FGP}, \mathrm{mmol} / \mathrm{l}$ \\
\hline Control & $39.63 \pm 8.51$ & $119.66 \pm 26.59$ & $1.19 \pm 0.13$ & $0.35 \pm 0.13$ & $5.43 \pm 0.84$ \\
\hline Model & $37.86 \pm 17.02$ & $163.84 \pm 14.85^{\mathrm{a}}$ & $1.16 \pm 0.17$ & $0.47 \pm 0.14$ & $7.27 \pm 3.20$ \\
\hline
\end{tabular}

${ }^{a} \mathrm{P}<0.05$ vs. control group. ALT, aspartate aminotransferase; AST, alanine aminotransferase; TC, total cholesterol; TG, total triglyceride; FGP, fasting plasma glucose.

Verification of miRNA (miR)-182, miR-29b-3p and miR-741-3p by reverse transcription-quantitative polymerase chain reaction. Liver tissue (100 $\mathrm{mg}$ ) was ground with $1 \mathrm{ml}$ pre-cooled TRIzol reagent in liquid nitrogen, and RNA was extracted, according to the manufacturer's protocol. Following this, $1 \mu \mathrm{l}$ of internal reference gene (U6) and $1 \mu 1$ of target gene-specific reverse transcription primers (miR-182, miR-29b-3p and miR-741-3p) were mixed with a $10 \mu 1$ RNA solution, placed in a PCR amplifier for $5 \mathrm{~min}$ at $65^{\circ} \mathrm{C}$ and then rapidly cooled on ice for 2 min. Following this, the First Strand cDNA Synthesis Kit (Toyobo Life Science, Osaka, Japan) was used to perform reverse transcription and the cDNA was subsequently stored at $-20^{\circ} \mathrm{C}$. A SYBR ${ }^{\circledR}$ Premix Ex Taq $^{\mathrm{TM}}$ kit was used for qPCR. The primers used for qPCR were as follows: miR-29b-3p forward 5'-AGTTGGGTGGAGGCTCTCC-3' and reverse, 5'-GCGACG AGCAAAAAGCTTGT-3'; miR-182 forward 5'-GCAATGGTA GAACTCACACCG-3' and reverse, 5'-GCGACGAGCAAA AAGCTTGT-3'; miR-741-3p forward 5'-TGGATGCCACGC TATGTAGAT-3'; and reverse, 5'-GCGACGAGCAAAAAG CTTGT-3'; U6 forward 5'-CCTGCTTCGGCAGCACA-3' and reverse, 5'-AACGCTTCACGAATTTGCGT-3'.

The reaction mixture for qPCR was composed of: $5.0 \mu \mathrm{l}$ 2X qPCR mix, $1.0 \mu \mathrm{l}$ primer working solution $(2.5 \mu \mathrm{M})$, $1.0 \mu \mathrm{l}$ cDNA, $2.8 \mu \mathrm{l}$ double distilled $\mathrm{H}_{2} \mathrm{O}$ and $0.2 \mu \mathrm{l}$ Rox. The thermocycling conditions used for qPCR were as follows: Pre-denaturation for $1 \mathrm{~min}$ at $95^{\circ} \mathrm{C}$; followed by 40 cycles of $95^{\circ} \mathrm{C}$ for $15 \mathrm{sec}, 58^{\circ} \mathrm{C}$ for $20 \mathrm{sec}$ and $72^{\circ} \mathrm{C}$ for $20 \mathrm{sec}$, followed by a final extension at $72^{\circ} \mathrm{C}$ for $5 \mathrm{~min}$. A dissolution curve was established by increasing the temperature from $72^{\circ} \mathrm{C}$ to $95^{\circ} \mathrm{C}$ at 20-sec time intervals. For RT-qPCR, U6 was used as the internal reference gene, and the experiments were performed in triplicate. The $2^{-\Delta \Delta \mathrm{Cq}}$ method was used for the quantification of miRNA expression (10).

Prediction and analysis of differentially expressed miRNAs and target genes. TargetScan (http://www.targetscan. org/mmu_71/), miRDB (http://www.mirdb.org/) and microRNA.org (http://www.mirbase.org/index.shtml) were used to predict target genes of the differentially expressed miRNAs. Following this, the functions and signaling pathways of target genes as well as pathway enrichment were investigated via Gene Ontology (GO; http://geneontology.org/) and Kyoto Encyclopedia of Genes and Genomes (KEGG) pathway analyses (http://www.genome.jp/kegg/ko.html).

Statistical analysis. Pairwise comparisons were performed using the Student's t test. SPSS 19.0 (IBM Corp., Armonk, NY, USA) was used to perform statistical analyses. Data are expressed as the mean \pm standard deviation. Experiments were repeated in triplicate. $\mathrm{P}<0.05$ was considered to indicate a statistically significant difference.

\section{Results}

Liver index, wet weight and dry weight prior to sacrifice. The liver index of the rats in the model group was revealed to be significantly increased compared with rats in the control group (Table I; $\mathrm{P}<0.05$ ); however, no significant differences were revealed regarding the liver wet weight and dry weight prior to sacrifice between the model group and the control group.

Biochemical indicators. The levels of AST in rats in the model group was significantly enhanced compared with rats in the control group; however, no significant differences regarding the levels of ALT, TG, TC and FGP were revealed between the model group and the control group (Table II; $\mathrm{P}<0.05$ ).

$H \& E$ staining of liver tissue. The results of the H\&E staining revealed that lobular structures of the rats in the control group were regular and clear. Hepatocytes were radially arranged around the central vein, with clear nuclei and uniform cytoplasm. Furthermore, there were no abnormalities in the hepatic sinusoid, limiting plate and portal areas (Fig. 1A and B). However, the lobular structures of the rats in the model group were disordered and varied in size and shape. With varying degrees of fatty degeneration and ballooning degeneration, 

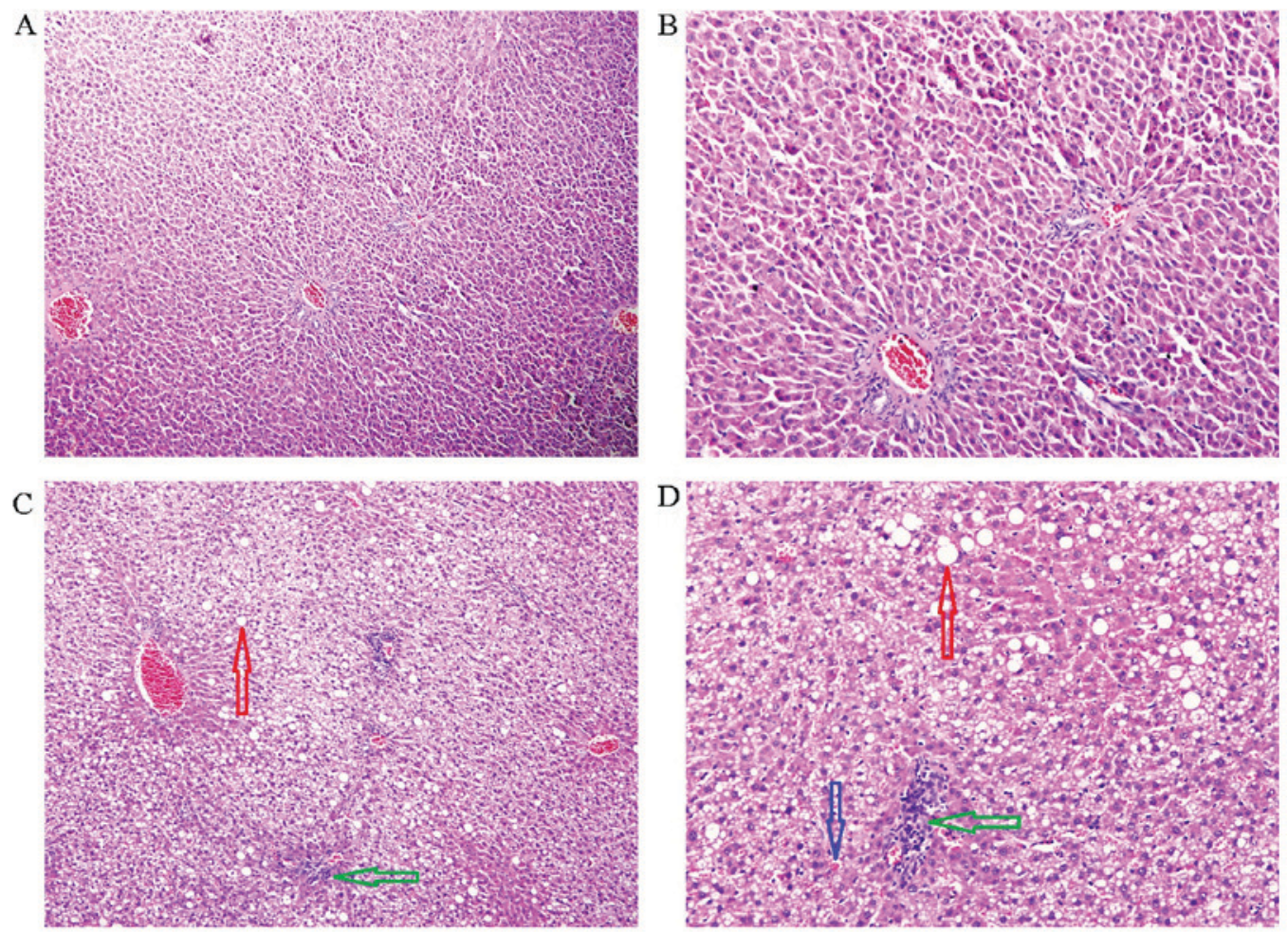

Figure 1. Hematoxylin and eosin staining of liver tissues obtained from rats in the (A) control group (magnification, x100) and (B) control group (magnification, $\mathrm{x} 200$ ). Lobular structure of liver tissues obtained from rats in the control group were regular, clear and did not present pseudo lobules; hepatocytes were radially arranged around the central vein with clear nucleus and uniform cytoplasm; and the hepatic sinusoid, limiting plate and portal area did not demonstrate any physiological abnormalities. Hematoxylin and eosin staining of liver tissues obtained from rats in the (C) model group (magnification, x100) and (D) model group (magnification, x200). Lobular structure of liver tissues obtained from rats in the model group were disordered and varied in size and shape. Numerous liver cells demonstrated point or focal necrosis (blue arrow), with varying degrees of fatty degeneration and balloon-like changes (red arrow); and inflammatory cells were revealed to be present in the interlobular and portal areas (green arrow).

numerous liver cells demonstrated localized or focal necrosis, and inflammatory cells were revealed to be present around the interlobular and portal areas (Fig. 1C and D). The NAS scores of the slices in the control group were 1-2 points, which excludes the diagnosis of NASH, and the slices in model group scored 6-7 points, which represents a potential NASH diagnosis.

Microarray results. Compared with the control group, 10 miRNAs (including 1 stem-loop miRNA) were revealed to be differentially expressed in the liver tissues of rats in the model group (Fig. 2 and Table III; $\mathrm{P}<0.05$ ). In the model group, rno-miR-743a-3p, rno-miR-741-3p, rno-miR-101a-3p, rno-miR-29b-3p and rno-miR-871-3p were markedly overexpressed in liver tissues compared with the control group; whereas rno-miR-344g, rno-miR-183-5p, rno-miR-32-3p, rno-miR-182 and stem-loop rno-miR-182 were markedly underexpressed in the liver tissues of the model group compared with the control group (Fig. 2 and Table III).

Prediction and analysis of the target genes of differentially expressed miRNAs. Compared with the control group, 10 miRNAs were differentially expressed in the liver tissues of rats in the model group. In the model group, rno-miR-743a-3p, rno-miR-741-3p, rno-miR-101a-3p, rno-miR-29b-3p and rno-miR-871-3p were markedly overexpressed in liver tissues compared with the control group; whereas rno-miR-344g,
rno-miR-183-5p, rno-miR-32-3p rno-mir-182 and rno-miR-182 were markedly underexpressed in the liver tissues of the model group compared with the control group (Fig. 3). Except for miR-182, rno-miR-743a-3p, rno-miR-344g, rno-miR-741-3p, rno-miR-32-3p and rno-miR-871-3p, the differentially expressed miRNAs had numerous target genes (Table IV), which indicated the wide role of miRNAs in numerous regulatory activities in vivo. In addition, GO enrichment analysis results revealed that the majority of target genes were revealed to be associated with protein binding (Fig. 4). Furthermore, GO enrichment analysis demonstrated that target genes were revealed to be associated with numerous cellular components, such as the cellular membrane (Fig. 5). Furthermore, the results of GO enrichment analysis revealed that target genes were revealed to be associated with numerous biological processes, particularly regarding the positive regulation of cellular process (Fig. 6). KEGG pathway cluster analysis of target genes revealed that differentially expressed miRNAs were associated with numerous signaling pathways, such as the mitogen-activated protein kinase (MAPK) signaling pathway (Fig. 7).

Determination of miR-182, miR-29b-3p and miR-741-3p levels by RT-qPCR. RT-qPCR was performed to investigate the levels of miR-182, miR-29b-3p and miR-741-3p between the model and control groups. The results revealed that the expression of miR-182, miR-29b-3p and miR-741-3p were increased in the 


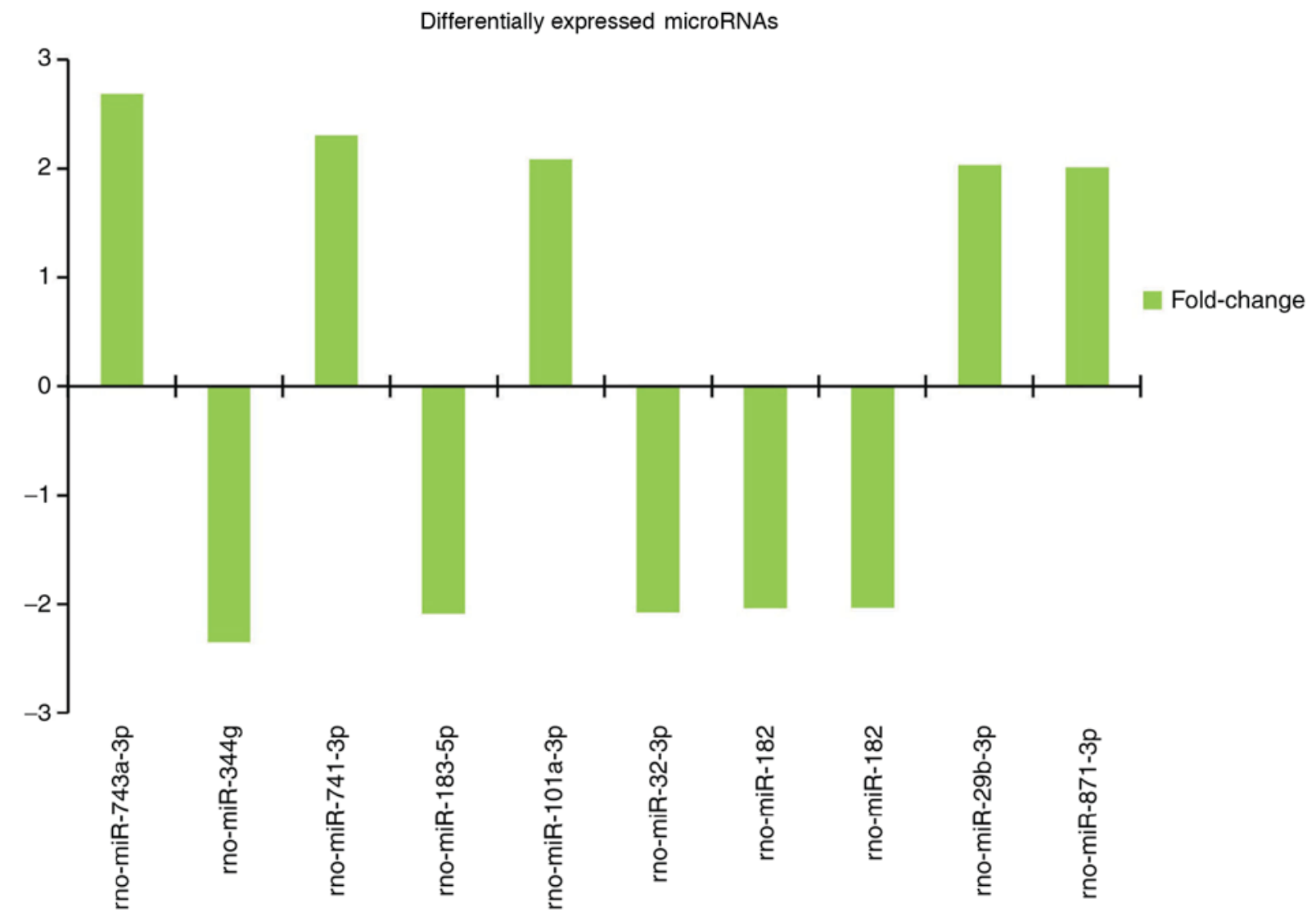

Figure 2. Differentially expressed microRNAs between the control group and model group. miR, microRNA.

model group compared with the control group (Fig. 8; $\mathrm{P}<0.05$ ). The results were largely consistent with the results obtained from miRNA gene chip analyses.

\section{Discussion}

miRNAs have been previously revealed to regulate numerous diseases, since their discovery in 1993 (8). Previous studies have also demonstrated the role of miRNAs in the pathogenesis of NAFLD $(7,8)$. In the present study, rats were fed a high-fat and high-sucrose diet for 12 weeks to induce the pathogenesis associated with NAFLD. A microarray was subsequently used to screen for miRNAs that could modulate the onset of NAFLD, which were further investigated using RT-qPCR. According to the results of microarray analysis, rno-miR-743a-3p, rno-miR-741-3p, rno-miR-101a-3p, rno-miR-29b-3p and rno-miR-871-3p were revealed to be markedly upregulated in the model group compared with the control group; whereas rno-miR-344g, rno-miR-183-5p, rno-miR-32-3p, rno-miR-182 and rno-mir-182 were revealed to be markedly downregulated in the model group compared with the control group. According to previous studies investigating the association between miRNAs and liver disease (11-45), as well as the results of miRNA gene chip analysis in the present study, miR-182, miR-29b-3p and miR-741-3p were selected for further investigation using RT-qPCR. The results demonstrated that the expression of miR-182, miR-29b-3p and miR-741-3p were increased in rats in the model group, which was largely in agreement with the results of miRNA gene chip analyses. Therefore, the results of the miRNA gene chip and further analyses of the differentially expressed miRNAs performed in the present study were considered to be reliable.

Numerous studies have previously investigated the role of miR-29 in liver fibrosis. Huang et al (11) suggested that serum miR-29 levels are negatively correlated between liver fibrotic stages and necroinflammation grades in patients with chronic hepatitis $\mathrm{B}$ virus infection. Among members of the miR-29 family, serum miR-29b levels have been demonstrated to be more easily detectable in patients with chronic hepatitis B virus infection. During progressive liver fibrosis, serum miR-29b levels, and not serum miR-29a or serum miR-29c expression levels, may act as a biomarker for the differentiation between absence of fibrosis or mild fibrosis (S0/1) and significant fibrosis (S2/3). In addition, miR-29b levels have been demonstrated to have a stronger correlation with ALT levels compared with miR-29a or miR-29c levels, thus indicating that miR-29b levels are more susceptible to regulation during systemic or liver inflammation induced by hepatitis B virus infection (11). Ogawa et al (12) revealed that miR-29b binds to the 3'-untranslated region of type I collagen protein in human stellate cells. The liver is the predominant organ responsible for metabolism, detoxification and drug metabolism. Cytochrome P450 2C19 (CYP2C19) represents an important factor during drug metabolism and has been demonstrated to be negatively correlated with the upregulation of hsa-miR-29a-3p in HepaRG cells and human liver tissues (12). Using predictive computer software, Yu et al (13) demonstrated that hsa-miR-29a-3p is able to bind to the coding 
Table III. Differentially expressed miRNAs between the model group and the control group.

A, Upregulated miRNAs

\begin{tabular}{lccc}
\hline Name & P-value & $\begin{array}{c}\text { Fold } \\
\text { change }\end{array}$ & $\begin{array}{c}\text { Sequence } \\
\text { type }\end{array}$ \\
\hline rno-miR-743a-3p & 0.207184292 & 2.686535062 & miRNA \\
rno-miR-741-3p & 0.257290163 & 2.303363333 & miRNA \\
rno-miR-101a-3p & 0.048881657 & 2.083797858 & miRNA \\
rno-miR-29b-3p & 0.109070634 & 2.032257670 & miRNA \\
rno-miR-871-3p & 0.263925290 & 2.011294025 & miRNA \\
\hline
\end{tabular}

B, Downregulated miRNAs

\begin{tabular}{lccc}
\hline Name & P-value & $\begin{array}{c}\text { Fold } \\
\text { change }\end{array}$ & $\begin{array}{c}\text { Sequence } \\
\text { type }\end{array}$ \\
\hline rno-miR-344g & 0.083684987 & -2.355189808 & miRNA \\
rno-miR-183-5p & 0.114185347 & -2.096263391 & miRNA \\
rno-miR-32-3p & 0.130397550 & -2.080240024 & miRNA \\
rno-miR-182 & 0.024688449 & -2.036088118 & miRNA \\
rno-miR-182 & 0.022652051 & -2.035236807 & stem-loop \\
\hline
\end{tabular}

miR/miRNA, microRNA.

region of $\mathrm{CYP} 2 \mathrm{C} 19$, and subsequent RNA migration experiments demonstrated that hsa-miR-29a-3p is able to inhibit the expression of CYP2C19 via direct binding to the homologous target sequence of the CYP2C19 transcript. By investigating the associations between hsa-miR-29a-3p and 374 important gene encoding drug metabolizing enzymes and transporters, Yu et al (14) revealed that hsa-miR-29a-3p targets the homologous target sequences of ATP binding cassette subfamily C member 6 , solute carrier family 22 member 7 and aldehyde dehydrogenase 5 family member mRNAs, which resulted the downregulation of drug metabolizing enzymes and transporters in human liver cells (14). In the present study, the results of the microarray analyses suggested that miR-29b-3p has a role in the onset of NAFLD. Despite numerous studies demonstrating that miR-29 is involved in fibrosis associated with multiple organs, including the liver, its role and regulatory pathways associated with NAFLD, to the best of our knowledge, have not been previously investigated $(15,16)$. Therefore, it is important to investigate miR-29 in greater depth.

The results of the present study revealed that there were $>40$ verified target genes of miR-29, most of which are associated with extracellular mechanisms. In addition to the regulation of transforming growth factor- $\beta /$ mothers against decapentaplegic homolog, the target genes have also been previously revealed to regulate the nuclear factor $(\mathrm{NF})-\kappa \mathrm{B}, \mathrm{Wnt} / \beta$-catenin and MAPK pathways (17). Xie et al (18) revealed that treatment with genistein inhibited the proliferation of tumor cells in numerous patients with myeloma via upregulation of miR-29b expression. During osteoblast differentiation, the expression of $\mathrm{miR}-29 \mathrm{a} / \mathrm{c}$ was demonstrated to be increased following the activation of the $\mathrm{Wnt} / \beta$-catenin signaling pathway. Furthermore, the expression of miR-29a/c was revealed to be decreased following treatment with an inhibitor of the Wnt/ $\beta$-catenin signaling pathway; whereas, upregulation of miR-29a expression was revealed to suppress the protein that inhibited the Wnt signaling pathway, which suggested that $\mathrm{miR}-29 \mathrm{a} / \mathrm{c}$ may regulate the $\mathrm{Wnt} / \beta$-catenin signaling pathway. Following subsequent investigation, it was demonstrated that the promoter of miR-29a contained the binding site for T-cell factor/lymphoid enhancer factor (19). In addition, as epithelial-mesenchymal transition (EMT) represents an important originator of fibrosis, it has been suggested that EMT may be associated with miR-29. Furthermore, the suppression of miR-29c expression in endometrial carcinoma during EMT suggested that miR-29c expression may be negatively associated with fibrosis.

The side effects exhibited by patients with suppressed miR-29b expression were not entirely harmful, despite miR-29b having a role in anti-fibrotic processes (20-22). Maegdefessel et al (20) suggested that downregulation of miR-29b expression may promote the occurrence of fibrosis, which reduces the frequency of aneurysm rupture. Furthermore, in numerous diseases exhibiting malignant tumors, miR-29 has been demonstrated to primarily reduce the proliferation of malignant cells and restrict the migration of tumor cells $(21,22)$. In patients with breast cancer with overexpression of human epidermal growth factor receptor 2 (HER2), miR-29b was revealed to suppress lymphatic metastasis and invasion via regulation of signal transducer and activator of transcription 3, which further subsequently regulated downstream HER2, cyclin D2 and matrix metallopeptidase 2 levels (22).

Despite numerous studies having demonstrated that miR-29b is involved in organ fibrosis and determined its associated molecular pathways, there are limited studies investigating the role of miR-29b in NAFLD (23). In general, miR-29b has been demonstrated to have an anti-fibrotic role; however, in the present study, the results demonstrated that miR-29b-3p was overexpressed in rats with NAFLD. Whether the overexpression of miR-29b-3p in NAFLD was due to a general adaption reaction or the result of an additional pathway requires further investigation. Future studies may aim to further elucidate the roles of miR-29b-3p in NAFLD.

In the present study, miR-182 was revealed to be overexpressed in rats with NAFLD. As a gene cluster, miR-182, miR-183 and miR-96 have been demonstrated to be involved in numerous biological processes, such as growth, development, differentiation and tumor formation.

The localized expression of the miR-182 gene cluster is variable. The miR-182 gene is predominantly expressed in all layers of the retina, except the retinal pigment epithelium. miR-183 has been revealed to be frequently expressed in the outer nuclear layer retina and the outer limiting membrane (24). In numerous diseases exhibiting skeletal muscle atrophy, miR-182 has been demonstrated to regulate skeletal atrophy-associated genes via targeting of forkhead box (FOX)O3 (25).

miR-182 has been revealed to be associated with the onset and progression of numerous malignant diseases, and is overexpressed in the majority of malignant diseases, functioning 


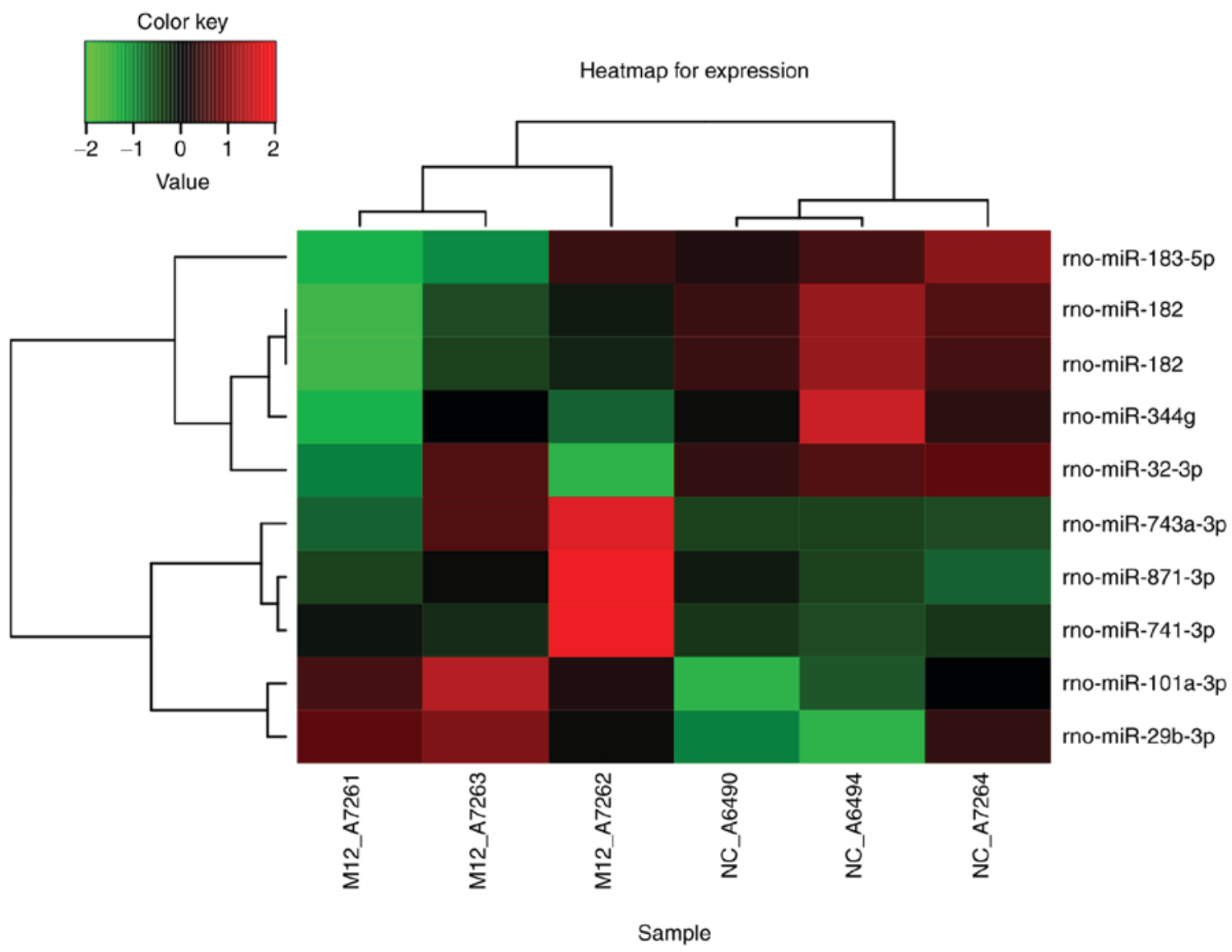

Figure 3. Cluster analysis of differentially expressed microRNAs. Red represents upregulated expression of miRNA. Green represents downregulated expression of miRNA. Compared with the control group, 10 miRNAs were differentially expressed in the liver tissues of rats in the model group. In the model group, rno-miR-743a-3p, rno-miR-741-3p, rno-miR-101a-3p, rno-miR-29b-3p and rno-miR-871-3p were markedly overexpressed in liver tissues compared with the control group; whereas rno-miR-344g, rno-miR-183-5p, rno-miR-32-3p rno-mir-182 and rno-miR-182 were markedly underexpressed in the liver tissues of the model group compared with the control group. miR, microRNA.

as an oncogene (24). Tessitore et al (26) demonstrated that 15 miRNAs are regulated in hepatic tissues and tumors during the NAFLD-nonalcoholic steatohepatitis-hepatocellular carcinoma (HCC) transition and that early involvement of miR-182 in the transition of liver injury, which was maintained until HCC initiation and development, suggested that early deregulation of miR-182 may be involved in the progression of hepatic disease. However, Huynh et al (27) demonstrated that miR-182 may attenuate the development of hepatic metastases of melanoma cells. Hirata et al (28) also revealed that downregulated miR-182 promotes the proliferation of prostate cancer cells by targeting the FOXF2, reversion inducing cysteine rich with kazal motifs and metastasis suppressor protein 1 genes.

In a number of types of cancer, miR-182 has been revealed to not have an inductive effect on carcinogenesis and cancer metastasis, for example in lung cancer and breast cancer (29). Zhu et al (30) demonstrated that miR-182 has a role in carcinostasis by downregulating the RAS p 21 protein activator 1 gene in squamous cell lung carcinoma. Zhang et al (31) revealed that miR-182 suppresses the proliferation and invasion of lung cancer cells. Wang et al (32) and Ning et al (33) demonstrated that miR-182 was overexpressed in lung adenocarcinoma cells and enhanced the proliferation of cancer cells via downregulation of programmed cell death
4 expression. Furthermore, Yang et al (34) revealed that miR-182 was overexpressed in lung cancer tissues and has an important role in the promotion of malignant cell proliferation and occurrence of epithelial mesenchymal transition; however, miR-182 was revealed to suppress the invasion and metastasis of cancer cells.

Numerous studies have investigated the role of miR-182 in breast cancer. Moskwa et al (35) demonstrated that miR-182 downregulates the BRCA1, DNA repair associated gene; this attenuates repair following DNA damage and subsequently induces further malignant cell proliferation, invasion and progression in breast cancer. Zhang et al (36) revealed that a miR-182 gene cluster may promote the occurrence of MET and invasion by suppressing the expression of breast cancer metastasis suppressor 1-like protein. Liu et al (37) and Lei et al (38) demonstrated that miR-182 promote cancer cell proliferation, migration and invasion via suppression of profilin 1 and P-loop containing nucleoside triphosphate hydrolases super family protein genes in patients with breast cancer.

Furthermore, numerous studies have investigated the association between miR-182 and other tumors or diseases. Spitschak et al (39) demonstrated that miR-182 is activated by highly aggressive M918T and $\mathrm{C} 634 \mathrm{~W}$ ret proto-oncogene mutations in a nuclear factor (NF)-kB-dependent manner; 
Table IV. Target genes of differentially expressed microRNAs.

miRNA Target

rno-miR-29b-3p ABCB6, APLNR, ATP1B1, ATP1B4, BAK1, BLMH, BMF, BSND, C1QTNF6, CD276, CDCA4, CHFR, CLDN1, CMPK1, COL3A1, COL5A3, CUEDC1, DPP3, DPYSL5, DUSP2, ELF2, ELN, EMP2, FERMT2, GEMIN2, GPR37, GRIP1, H2AFY, HAS3, HBP1, HMGCR, HMGCS1, HMGN3, IFI30, IREB2, ITGB1, JOSD1, KLF4, KLHDC3, KLHL25, LAMTOR1, LYSMD1, MLLT11, MYCN, NANP, NARF, NFIA, PAIP2, PALM, PARG, PCDHA1, PCDHA10, PCDHA11, PCDHA12, PCDHA13, PCDHA2, PCDHA3, PCDHA4, PCDHA5, PCDHA6, PCDHA7, PCDHA8, PCDHAC1, PCDHAC2, PLP1, PMP22, PPIC, PPP2CA, PRKRA, PRR3, RAB30, RLIM, RNF39, SGK1, SMPD3, SMS, SNX24, STMN2, STRN3, TFEB, TMEM183A, TNFAIP1, TNFRSF1A, TRAK2, TRIM63, TSPAN4, TUBB2B, XKR4, XKR7, YBX3, ZFP36

rno-miR-182 ADCY6, ANXA11, ARF4, ARHGDIA, B4GALT6, BDNF, BNIP3, C2CD2, CCDC117, CDO1, CFL1, CITED2, CNN3, CTTN, DNAJB9, DYRK1A, EIF5, FGF9, FLOT1, FMR1, GK, GPR85, IGSF10, KDELR1, KLF15, KPNA3, L1CAM, MAP1LC3B, MFAP3, NRCAM, PAIP2, PC, PLD1, PPP1R2, PPP3R1, PRPF4B, RNF44, RTN4, SEPT7, SH3BP4, SLC4A1, SMAD1, STK19, TMEM50B, TOB1, TPGS2, TSNAX, TXNL1, VAMP3, WIPF1, XBP1, ZC3H15

rno-miR-183-5p ADCY6, AMD1, AP3M1, BNIP3L, BTG1, CELSR3, CX3CL1, DAP, EZR, GNG5, GPR85, HN1, IDH2, IRS1, KCNJ14, KCNK10, KCNK2, KLHL24, MAL2, MAPK8IP1, NCS1, NR3C1, NRG1, PLCB4,

PLEKHA3, PPP2CA, PPP2CB, PPP2R2A, PSEN2, RCN2, SEL1L, SERP1, SLC25A20, SMPD3, SNX1, SPRY2, SRSF2, TMEM150A, XKR7, YPEL5

rno-miR-101a-3p ABCC5, ABHD17B, ANKZF1, ATXN1, BICD2, BRD8, CACNB2, CAV3, CDYL, CLDN11, CTCF, DDIT4, DLGAP3, DR1, DSTYK, DUSP1, EMP1, EMP2, GJA1, GLRA2, GPR85, HAS2, HNRNPF, KAT7, LRRC4, LRRN1, MOB4, MORN4, MYCN, NDFIP1, OGT, PIP5K1C, PLCG1, PRPF4B, RAB1A, RASD2, RBBP7, RHOQ, RXRB, SH2B3, SLC30A4, STC1, STK25, SUB1, TGFBR1, UBE2A, UBR7

miR, microRNA.

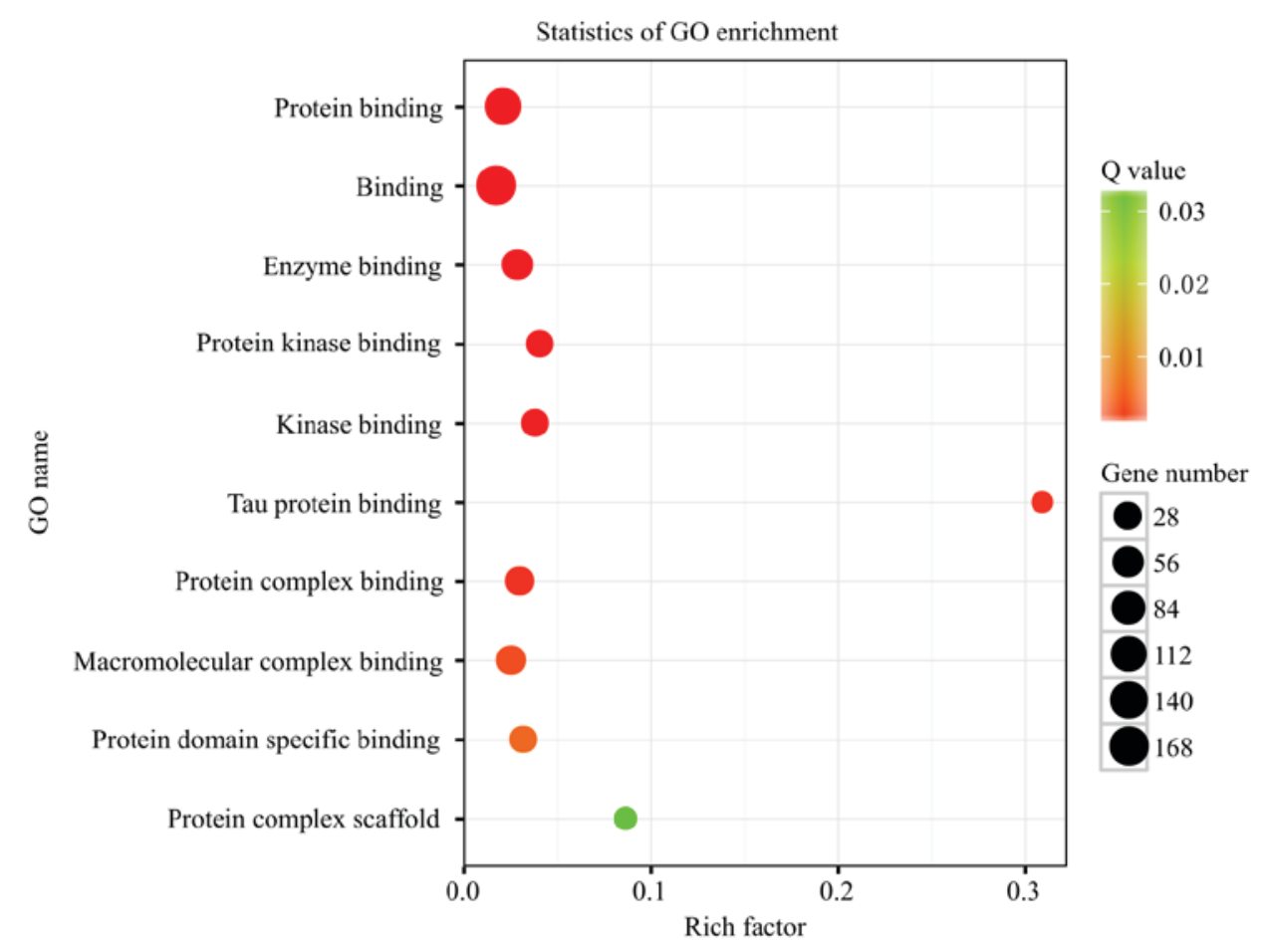

Figure 4. GO analysis was performed to investigate the molecular functions of target genes. The majority of target genes were revealed to be associated with protein binding. GO, Gene Ontology.

and that miR-182 promotes cancer invasion by linking the RET oncogene activated NF- $\mathrm{NB}$ to loss of the hes family
bHLH transcription factor $1 /$ Notch1 regulatory circuit. In colon cancer, miR-182 has been revealed to promote 


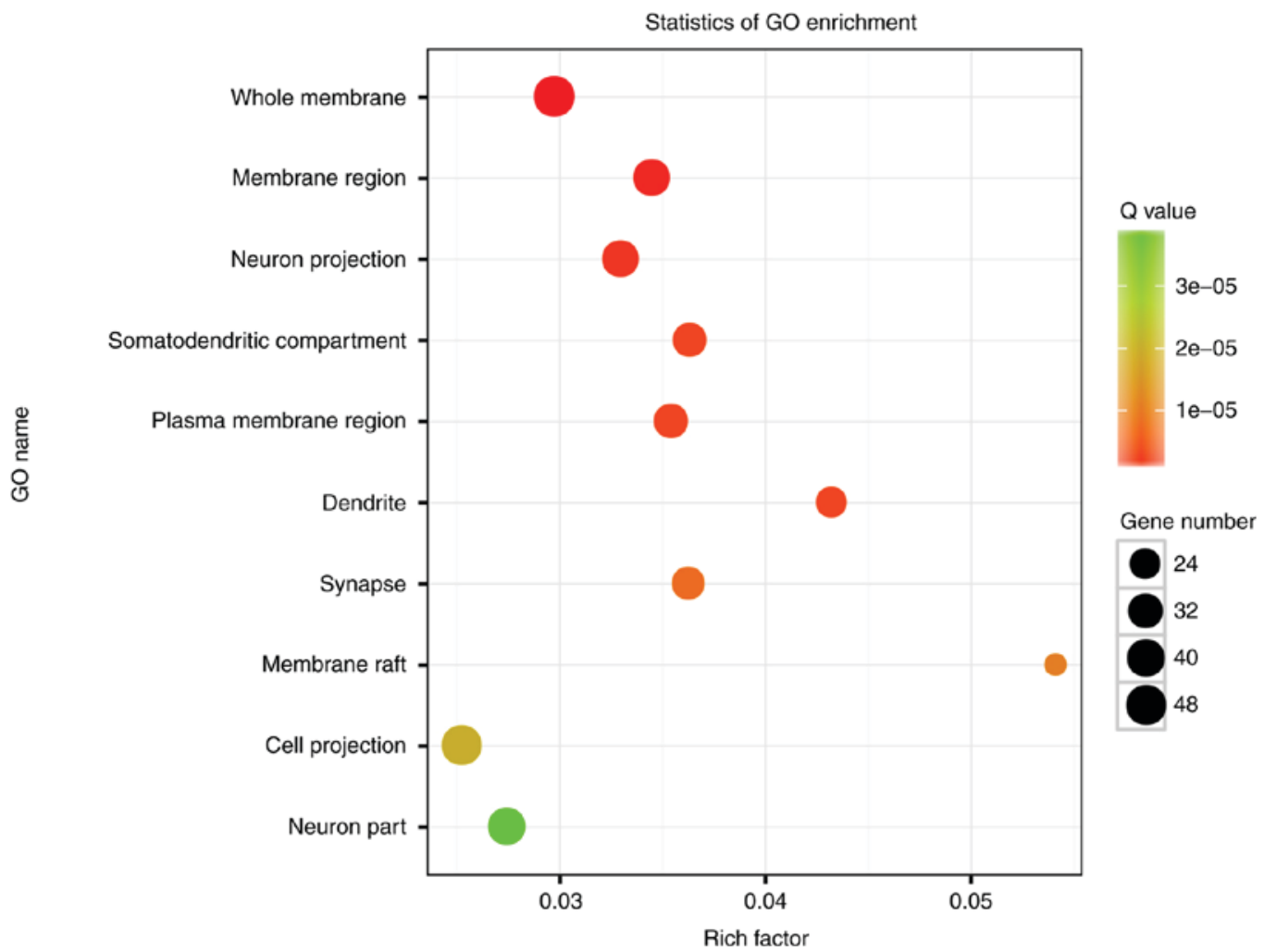

Figure 5. GO analysis was performed to investigate the cellular components associated with target genes. Target genes were revealed to be associated with numerous cellular components. GO, Gene Ontology.

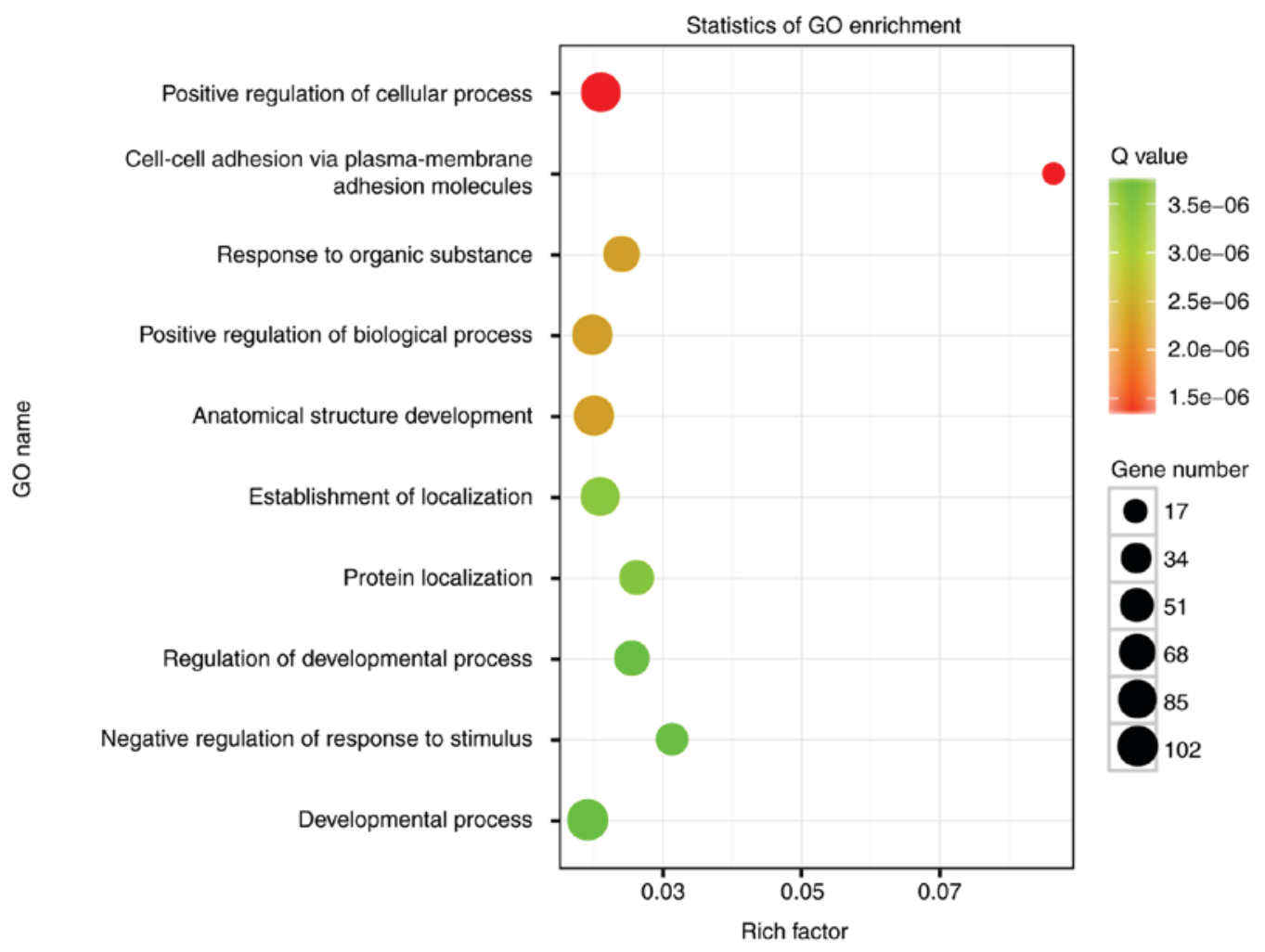

Figure 6. GO analysis was performed to investigate biological processes associated with target genes. Target genes were revealed to be associated with numerous biological processes, such as the positive regulation of cellular process. GO, Gene Ontology.

proliferation and transfer via suppression of the special AT-rich sequence-binding protein 2 gene (40). miR-182-5p was demonstrated to function as a cancer suppressor gene via suppression of cancer cell proliferation by targeting 


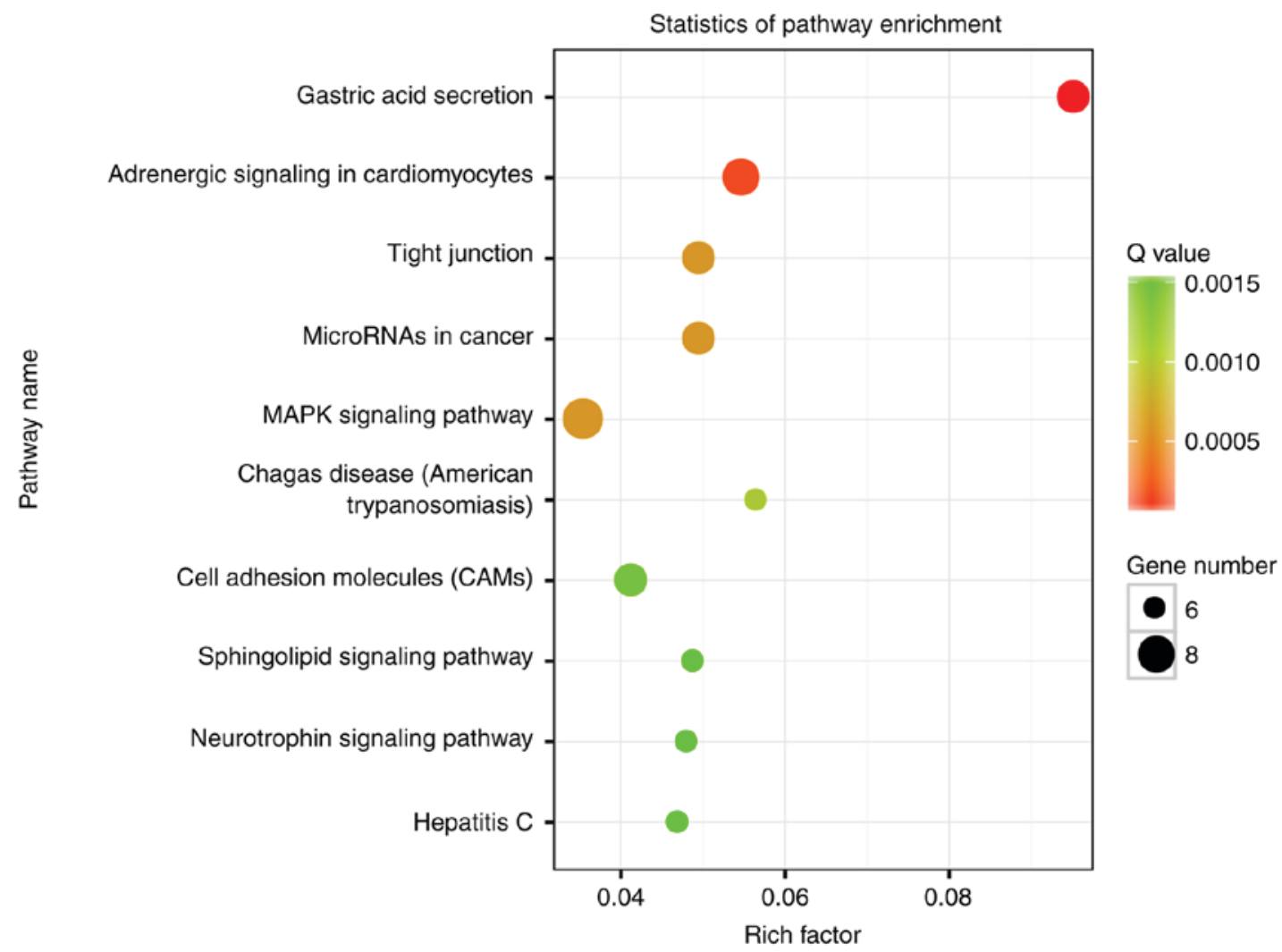

Figure 7. Kyoto Encyclopedia of Genes and Genomes pathway cluster analysis of target genes. Differentially expressed miRNAs were revealed to be associated with gastric acid secretion, cardiac adrenergic signals, tight junctions, miRNAs involved in cancer, MAPK signaling pathways, Chagas disease (American trypanosomiasis), cell adhesion molecules, sphingolipid signaling pathways, neurotrophin signaling pathways and hepatitis C. miRNAs, microRNAs; MAPK, mitogen-activated protein kinase.

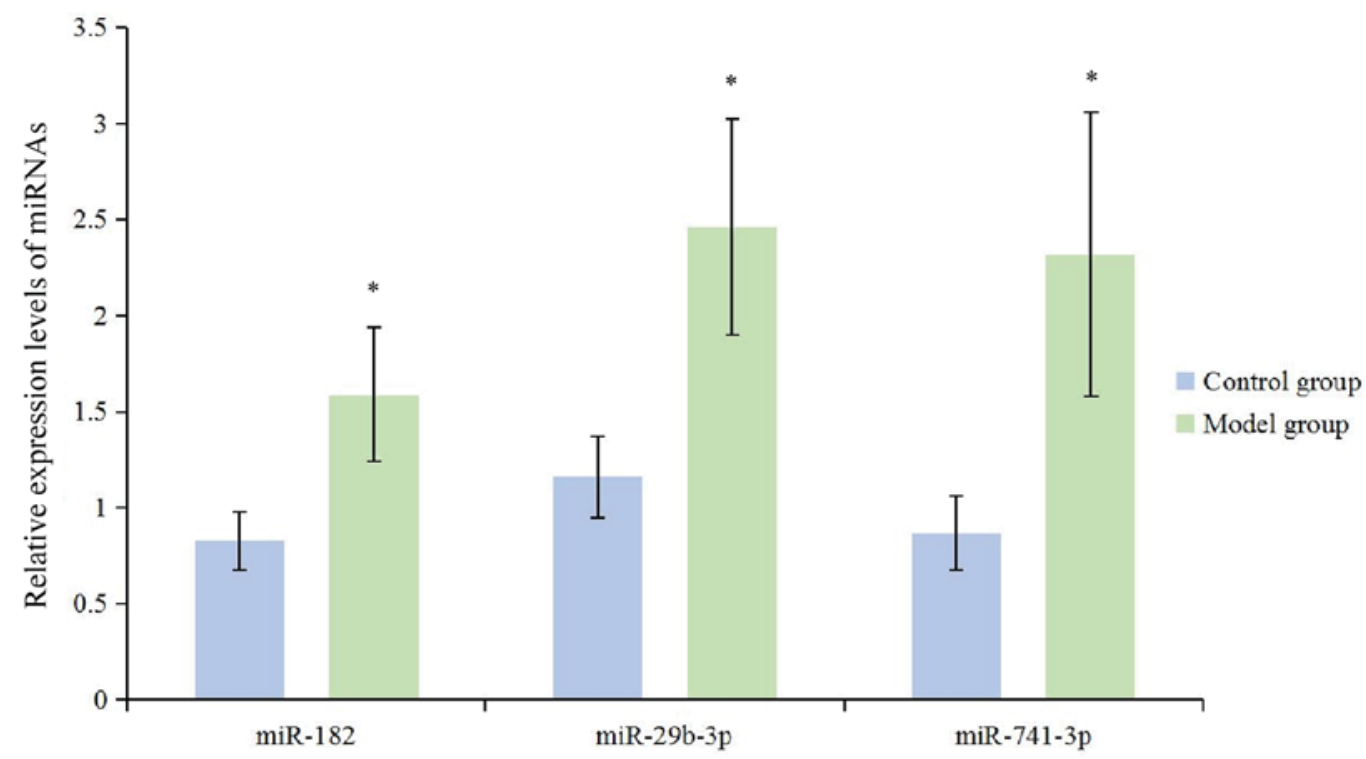

Figure 8. Reverse transcription-quantitative polymerase chain reaction was performed to investigate the expression levels of miR-182, miR-29b-3p and miR-741-3p in the model and control groups. Quantification of protein expression levels was determined using the $2^{-\Delta \Delta C q}$ method and presented relative to the levels expressed by the control group. The results revealed that the expression of miR-182, miR-29b-3p and miR-741-3p were increased in the model group compared with the control group, which were largely consistent with the results obtained from microRNA gene chip analyses. "P $<0.05$ vs. control group. mIR, microRNA.

the pathway of protein kinase $\mathrm{B} / \mathrm{FOXO} 3 \mathrm{a}$ in renal cell carcinoma (41). In osteosarcoma, miR-182 has been demonstrated to reduce the growth rate and invasive ability of cancer cells via regulation of $\mathrm{T}$ cell lymphoma invasion and metastasis 1 (42). Chen et al (43) revealed that the diagnostic specificity and sensitivity of increased miR-182 levels in 
blood is greater compared with the diagnostic specificity and sensitivity of CA199 in patients with pancreatic cancer. By studying the expression of miR-182 in liver cells and natural killer (NK) cells with hepatitis $\mathrm{C}$ virus (HCV) infection, $\mathrm{El}$ Sobky et al (44) demonstrated that miR-182 was downregulated in the liver and NK cells in patients with HCV infection, which suggested that miR-182 may have a role in HCV viral replication in NK and Huh7 cells. In the model of chronic stress, Li et al (45) revealed that the upregulation of miR-182 was associated with the downregulation of brain derived neurotrophic factor (BDNF), which aggravates the symptoms resulting from hippocampus depression with chronic stress. Furthermore, BDNF represents a target gene of miR-182 (45).

The aforementioned studies demonstrated that the miR-182 family does not solely exhibit pro-carcinogenesis or carcinostasis functions, which may be due to its variable effects on different organs and pathways. However, few studies investigating fibrosis in NAFLD have been performed $(7,16)$. The present study demonstrated that miR-182 was overexpressed and that miR-183-5p was stably downregulated during NAFLD progression, which suggested that it may be involved in the process of NAFLD.

The present study screened for differentially expressed miRNAs using microarray analysis and subsequently investigated the results further using RT-qPCR. Data regarding miR-29a-3p and miR-182 may be found in numerous databases (34-44). However, to the best of our knowledge, there was no obtainable data regarding miR-741-3p in databases, including National Center for Biotechnology Information, PubMed, China Academic Journals, Wanfang Data and VIP (http://www.cqvip.com/), which demonstrated that miR-741-3p requires investigation in future studies.

The present study determined the target genes of differentially expressed miRNAs in NAFLD via bioinformatics analyses, and determined pathways associated with target genes via GO analysis and KEGG pathway analyses. According to the KEGG pathway analysis, the results demonstrated that differentially expressed miRNAs were predominantly involved in 'gastric acid secretion', 'cardiac adrenergic signals', 'tight junctions', 'cancer', 'MAPK signaling pathways', 'Chagas disease (American trypanosomiasis)', 'cell adhesion molecules', 'sphingolipid signaling pathways', 'neurotrophin signaling pathways' and 'hepatitis C'; which suggested that miRNAs are involved in a wide range of processes, including signal transduction, stress reaction, proliferation, differentiation and cancer. The complex regulatory network underlying NAFLD requires further investigation.

Numerous studies have investigated the role of miRNAs in the pathogenesis of diseases. Research regarding NAFLD is relatively limited, and research investigating the underlying molecular mechanisms of NAFLD is also limited. The results of the present study determined via microarray analysis that numerous miRNAs may be involved in the pathogenesis of NAFLD, and laid the foundation for further study investigating the NAFLD pathway and the development of therapeutic treatments.

\section{Acknowledgements}

Not applicable.

\section{Funding}

The present study was funded by the Developmental Fund of the Sichuan Science and Technology Agency Luzhou City-Luzhou Medical College Combined Fund (grant no. 14JC0087).

\section{Availability of data and materials}

All data generated or analyzed during this study are included in this published article.

\section{Authors' contributions}

JN and CPL conceived and designed the study. JN and HJL performed the experiments. JN, CPL, HJL, XC and XZ contributed to data analyses and data interpretation. JN and CPL drafted the manuscript. All authors read and approved the final manuscript.

\section{Ethics approval and consent to participate}

The protocol of this study was approved by Ethics Committee of the Affiliated Hospital of Southwest Medical University in 2015 (reference no. 2015056).

\section{Patient consent for publication}

Not applicable.

\section{Competing interests}

The authors declare that they have no competing interests.

\section{References}

1. Miyata $\mathrm{H}$ and Miyata S: Speculation of the time-dependent change of FIB4 index in patients with nonalcoholic fatty liver disease: A retrospective study. Can J Gastroenterol Hepatol 2018: 5323061, 2018.

2. Yoo W, Gjuka D, Stevenson HL, Song X, Shen H, Yoo SY, Wang J, Fallon M, Ioannou GN, Harrison SA and Beretta L: Fatty acids in non-alcoholic steatohepatitis: Focus on pentadecanoic acid. PLoS One 12: e0189965, 2017.

3. Zheng X, Gong L, Luo R, Chen H, Peng B, Ren W and Wang Y: Serum uric acid and non-alcoholic fatty liver disease in non-obesity chinese adults. Lipids Health Dis 16: 202,2017.

4. Hossain MA, Lee SJ, Park NH, Birhanu BT, Mechesso AF, Park JY, Park EJ, Lee SP, Youn SJ and Park SC: Enhancement of lipid metabolism and hepatic stability in fat-induced obese mice by fermented cucurbita moschata extract. Evid Based Complement Alternat Med 2018: 3908453, 2018.

5. Ma KL, Ruan XZ, Powis SH, Chen Y, Moorhead JF and Varghese Z: Inflammatory stress exacerbates lipid accumulation in hepatic cells and fatty livers of apolipoprotein E knockout mice. Hepatology 48: 770-781, 2008.

6. Tilg $\mathrm{H}$ and Moschen AR: Evolution of inflammation in nonalcoholic fatty liver disease: The multiple parallel hits hypothesis. Hepatology 52: 1836-1846, 2010.

7. Boutari C, Perakakis N and Mantzoros CS: Association of adipokines with development and progression of nonalcoholic fatty liver disease. Endocrinol Metab (Seoul) 33: 33-43, 2018.

8. Zhang T, Zhao X, Steer CJ, Yan G and Song G: A negative feedback loop between microRNA-378 and nrf1 promotes the development of hepatosteatosis in mice treated with a high fat diet. Metabolism: April 3, 2018 (Epub ahead of print).

9. Ahamid M, Mahroum N, Bragazzi NL, Shalaata K, Yavne Y, Adawi M, Amital H and Watad A: Folate and B12 levels correlate with histological severity in NASH patients. Nutrients 10: E440, 2018. 
10. Livak KJ and Schmittgen TD: Analysis of relative gene expression data using real-time quantitative PCR and the 2(-Delta Delta C(T)) method. Methods 25: 402-408, 2001.

11. Huang C, Zheng JM, Cheng Q, YU KK, Ling QX, Chen MQ and LI N: Serum microRNA-29 levels correlate with disease progression in patients with chronic hepatitis B virus infection. J Dig Dis 15: 614-621, 2014.

12. Ogawa T, Iizuka M, Sekiya Y, Yoshizato K, Ikeda K and Kawada N: Suppression of type I collagen production by microRNA-29b in cultured human stellate cells. Biochem Biophys Res Commun 391: 316-321, 2010.

13. Yu D, Green B, Tolleson WH, Jin Y, Mei N, Guo Y, Deng H, Pogribny I and Ning B: MicroRNA hsa-miR-29a-3p modulates CYP2C19 in human liver cells. Biochem Pharmacol 98: 215-223, 2015.

14. Yu D, Tolleson WH, Knox B, Jin Y, Guo L, Guo Y, Kadlubar SA and Ning B: Modulation of ALDH5A1 and SLC22A7 by MicroRNA hsa-miR-29a-3p in human liver cells. Biochem Pharmacol 98: 671-680, 2015.

15. Liu MX, Gao M, Li CZ, Yu CZ, Yan H, Peng C, Li Y, Li CG, Ma ZL, Zhao Y, et al: Dicer1/miR-29/HMGCR axis contributes to hepatic free cholesterol accumulation in mouse non-alcoholic steatohepatitis. Acta Pharmacol Sin 38: 660-671, 2017.

16. Willeit P, Skroblin P, Kiechl S, Fernández-Hernando $C$ and Mayr M: Liver microRNAs: Potential mediators and biomarkers for metabolic and cardiovascular disease? Eur Heart J 37: 3260-3266, 2016.

17. Le LT, Swingler TE, Crowe N, Vincent TL, Barter MJ, Donell ST, Delany AM, Dalmay T, Young DA and Clark IM: The microRNA-29 family in cartilage homeostasis and osteoarthritis. J Mol Med (Berl) 94: 583-596, 2016.

18. Xie J, Wang J and Zhu B: Genistein inhibits the proliferation of human multiple myeloma cells through suppression of nuclear factor- $\kappa \mathrm{B}$ and upregulation of microRNA-29b. Mol Med Rep 13: $1627-1632,2016$

19. Zhang S, Wang Z, Zhu J, Xu T, Zhao Y, Zhao H, Tang F, Li Z Zhou J, Gao D, et al: Carnosic acid alleviates BDL-induced liver fibrosis through miR-29b-3p-Mediated inhibition of the high-mobility group box 1/toll-like receptor 4 signaling pathway in rats. Front Pharmacol 8: 976, 2018

20. Maegdefessel L, Azuma J and Tsao PS: MicroRNA-29b regulation of abdominal aortic aneurysm development. Trends Cardiovasc Med 24: 1-6, 2014

21. Franceschetti T, Kessler CB, Lee SK and Delany AM: miR-29 promotes murine osteoclastogenesis by regulating osteoclast commitment and migration. J Biol Chem 288: 33347-33360, 2013.

22. Kwon JJ, Nabinger SC, Vega Z, Sahu SS, Alluri RK, Abdul-Sater Z, Yu Z, Gore J, Nalepa G, Saxena R, et al: Pathophysiological role of microRNA-29 in pancreatic cancer stroma. Sci Rep 5: 11450, 2015.

23. Qin L, Li R, Zhang J, Li A and Luo R: Special suppressive role of miR-29b in HER2-positive breast cancer cells by targeting Stat3. Am J Transl Res 7: 878-890, 2015

24. Wang L, Dong F, Reinach PS, He D, Zhao X, Chen X, Hu DN and Yan D: MicroRNA-182 suppresses HGF/SF-induced increases in retinal pigment epithelial cell proliferation and migration through targeting c-Met. PLoS One 11: e0167684, 2016.

25. Hudson MB, Rahnert JA, Zheng B, Woodworth-Hobbs ME, Franch HA and Price SR: miR-182 attenuates atrophy-related gene expression by targeting FoxO3 in skeletal muscle. Am J Physiol Cell Physiol 307: C314-C319, 2014.

26. Tessitore A, Cicciarelli G, Vecchio FD, Gaggiano A, Verzella D, Fischietti M, Mastroiaco V, Vetuschi A, Sferra R, Barnabei R, et al: MicroRNA expression analysis in high fat diet-induced NAFLD-NASH-HCC progression: Study on C57BL/6J mice. BMC Cancer 16: 3, 2016.

27. Huynh C, Segura MF, Gaziel-Sovran A, Menendez S, Darvishian F, Chiriboga L, Levin B, Meruelo D, Osman I, Zavadil J, et al: Efficient in vivo microRNA targeting of liver metastasis. Oncogene 30: 1481-1488, 2011.

28. Hirata H, Ueno K, Shahryari V, Deng G, Tanaka Y, Tabatabai ZL, Hinoda Y and Dahiya R: MicroRNA-182-5p promotes cell invasion and proliferation by down regulating FOXF2, RECK and MTSS1 genes in human prostate cancer. PLoS One 8: e55502, 2013.
29. Peng Z, Pan L, Niu Z, Li W, Dang X, Wan L, Zhang R and Yang S: Identification of microRNAs as potential biomarkers for lung adenocarcinoma using integrating genomics analysis. Oncotarget 8: 64143-64156, 2017.

30. Zhu YJ, Xu B and Xia W: Hsa-mir-182 downregulates RASA1 and suppresses lung squamous cell carcinoma cell proliferation. Clin Lab 60: 155-159, 2014.

31. Zhang L, Liu T, Huang Y and Liu J: microRNA-182 inhibits the proliferation and invasion of human lung adenocarcinoma cells through its effect on human cortical actin-associated protein. Int J Mol Med 28: 381-388, 2011.

32. Wang $M$, Wang Y, Zang W, Wang $\mathrm{H}$, Chu H, Li P, Li M, Zhang G and Zhao G: Downregulation of microRNA-182 inhibits cell growth and invasion by targeting programmed cell death 4 in human lung adenocarcinoma cells. Tumor Biol 35: 39-46, 2014

33. Ning FL, Wang F, Li ML, Yu ZS, Hao YZ and Chen SS: MicroRNA-182 modulates chemosensitivity of human non-small cell lung cancer to cisplatin by targeting PDCD4. Diagn Pathol 9: $143,2014$.

34. Yang WB, Chen PH, Hsu T I, Fu TF, Su WC, Liaw H, Chang WC and Hung JJ: Sp1-mediated microRNA-182 expression regulates lung cancer progression. Oncotarget 5: 740-753, 2014.

35. Moskwa P, Buffa FM, Pan Y, Panchakshari R, Gottipati P, Muschel RJ, Beech J, Kulshrestha R, Abdelmohsen K, Weinstock DM, et al: miR-182-mediated downregulation of BRCA1 impacts DNA repair and sensitivity to PARP inhibitors. Mol Cell 41: 210-220, 2011.

36. Zhang W, Qian P, Zhang X, Zhang M, Wang H, Wu M, Kong X, Tan S, Ding K, Perry JK, et al: Autocrine/paracrine human growth hormone-stimulated MicroRNA 96-182-183 cluster promotes epithelial-mesenchymal transition and invasion in breast cancer. J Biol Chem 290: 13812-13829, 2015.

37. Liu H, Wang Y, Li X, Zhang YJ, Li J, Zheng YQ, Liu M, Song X and $\mathrm{Li} \mathrm{XR:} \mathrm{Expression} \mathrm{and} \mathrm{regulatory} \mathrm{function} \mathrm{of} \mathrm{miRNA-182} \mathrm{in}$ triple-negative breast cancer cells through its targeting of profilin 1. Tumor Biol 34: 1713-1722, 2013.

38. Lei R, Tang J, Zhuang X, Deng R, Li G, Yu J, Liang Y, Xiao J, Wang HY, Yang Q and Hu G: Suppression of MIM by microRNA-182 activates RhoA and promotes breast cancer metastasis. Oncogene 33: 1287-1296, 2014

39. Spitschak A, Meier C, Kowtharapu B, Engelmann D and Pütze BM: MiR-182 promotes cancer invasion by linking RET oncogene activated NF-kB to loss of the HES1/Notch1 regulatory circuit. Mol Cancer 16: 24, 2017.

40. Yang MH, Yu J, Jiang DM, Li WL, Wang S and Ding YQ: microRNA-182 targets special AT-rich sequence-binding protein 2 to promote colorectal cancer proliferation and metastasis. J Transl Med 12: 109, 2014

41. Xu X, Wu J, Li S, Hu Z, Xu X, Zhu Y, Liang Z, Wang X, Lin Y, Mao Y, et al: Downregulation of microRNA-182-5p contributes to renal cell carcinoma proliferation via activating the AKT/FOXO3a signalingpathway. Mol cancer 13: 109, 2014.

42. Hu J, Lv G, Zhou S, Zhou Y, Nie B, Duan H, Zhang Y and Yuan X: The downregulation of MiR-182 is associated with the growth and invasion of osteosarcoma cells through the regulation of TIAM1 expression. PLoS One 10: e0121175, 2015.

43. Chen Q, Yang L, Xiao Y, Zhu J and Li Z: Circulating microRNA-182 in plasma and its potential diagnostic and prognostic value for pancreatic cancer. Med Oncol 31: 225, 2014.

44. El Sobky SA, El-Ekiaby NM, Mekky RY, Elemam NM, Mohey Eldin MA, El-Sayed M, Esmat G and Abdelaziz AI: Contradicting roles of miR-182 in both NK cells and their host target hepatocytes in HCV. Immunol Lett 169: 52-60, 2016

45. Li Y, Li S, Yan J, Wang D, Yin R, Zhao L, Zhu Y and Zhu X: miR-182(microRNA-182) suppression in the hippocampus evokes antidepressant-like effects in rats. Prog Neuropsychopharmacol Biol Psychiatry 65: 96-103, 2016.

This work is licensed under a Creative Commons Attribution-NonCommercial-NoDerivatives 4.0 International (CC BY-NC-ND 4.0) License. 